\title{
Efeitos dos níveis de energia, lisina e metionina + cistina sobre o desempenho e o rendimento de carcaça de frangos de corte
}

\section{Laís Maria Brito Lima ${ }^{1}$, Leonardo José Camargos Lara ${ }^{1}$, Nelson Carneiro Baião ${ }^{1}$, Silvana de Vasconcelos Cançado ${ }^{2}$, Bruna Cypreste Michell ${ }^{1}$, Fernanda Carolina Ferreira ${ }^{1}$}

\footnotetext{
${ }^{1}$ Escola de Veterinária, Departamento de Zootecnia - UFMG.

2 Escola de Veterinária, DTIPOA - UFMG.
}

\begin{abstract}
RESUMO - Avaliaram-se os efeitos dos níveis de energia, lisina, metionina + cistina na ração sobre o desempenho e os rendimentos de carcaça e cortes de frangos de corte. O delineamento experimental foi o inteiramente ao acaso, em esquema fatorial $(3 \times 2)$, composto de seis tratamentos e oito repetições (quatro para machos e quatro para fêmeas). Os tratamentos foram definidos pelos níveis de energia (baixo, médio e alto), lisina e metionina + cistina (padrão ou 10\% superiores ao recomendado) e pelo período de criação (1 a 45 dias de idade). Em frangos machos, níveis médios de energia (3.000, 3.100 e $3.200 \mathrm{kcal} / \mathrm{kg}$, respectivamente, nas rações inicial, de crescimento e final) e níveis normais de aminoácidos proporcionam maior ganho peso aos 45 dias de idade, no entanto, para obtenção de maior rendimento de peito, o nível mais alto de aminoácidos é mais recomendável. Em fêmeas, para maior ganho de peso até os 40 dias de idade, devem ser associados níveis médios de energia e níveis mais altos de aminoácidos.
\end{abstract}

Palavras-chave: aminoácidos, desempenho, energia, frangos de corte, rendimento de carcaça

\section{Effect of energy, lysine and methionine and cystine levels on performance and carcass yield of broiler chickens}

\begin{abstract}
The effects of dietary energy, lysine and methionine + cystine levels on performance, carcass and cuts yields of male and female broiler chickens were evaluated. The experiment was analyzed as a completely randomized experimental design in a $3 \times 2$ factorial arrangement composed by six diets and eight replications (four males and four females). The diets consisted of energy (low, middle and high) and lysine and methionine + cystine (standard and $+10 \%)$ levels and of raising period ( 1 to 45 days old). Male broilers fed diets with 3,000, 3,100 and 3,200 kcal/kg, respectively, in the initial, growing and standard levels of amino acids showed better weight gain at 45 days old, however, for the best breast yield, the highest amino acid level was the most indicated. Middle energy and high amino acids levels are indicated for greater weight up to 40 days old, in females.
\end{abstract}

Key Words: amino acid, broiler, carcass yield, energy, performance

\section{Introdução}

A relação ideal de energia:proteína e a utilização de proteína ideal e de aminoácidos digestíveis têm grande influência no desempenho de frangos de corte. São crescentes as exigências do mercado de produtos avícolas, que busca maior rendimento de carcaças, de cortes e de produtos processados em relação ao desempenho do frango vivo. Para a indústria este avanço representa o aumento do valor agregado ao produto que será comercializado (Moran, 1992; Luchesi, 2000).

Em pesquisa com frangos de corte alimentados com rações contendo níveis de lisina digestível de 0,91 a 1,44\% e relações da lisina:metionina + cistina, treonina, triptofano, arginina, isoleucina e valina de 100:73, 65, 16, 105, 66 e 80\%, respectivamente, Lemme (2003) observou efeito linear dos níveis de aminoácidos sobre o ganho de peso e a conversão alimentar. Com o aumento dos níveis de aminoácidos, também houve efeito linear sobre o rendimento de peito.

Wijtten et al. (2004) observaram que níveis mais altos de proteína ideal na ração nas fases inicial e de crescimento determinaram maior ganho de peso e melhor conversão alimentar. O rendimento de peito não foi afetado, mas a porcentagem de gordura abdominal decresceu de forma linear e inversa ao nível de proteína ideal na dieta inicial. 
O nível energético de rações para frangos de corte afeta tanto o desempenho biológico quanto o econômico. Quando se aumenta o nível energético da dieta sem o adequado ajuste de nutrientes como proteína, aminoácidos, vitaminas e minerais, ocorre desequilíbrio dos nutrientes, que provoca deposição excessiva de gordura na carcaça e diminuição da taxa de crescimento (Lesson \& Summers, 2001).

Avaliando níveis crescentes de energia com relação constante do perfil de aminoácidos em dietas para frangos de corte, Langhout \& Wijtten (2005) observaram que as respostas ao aumento de aminoácidos essenciais sobre o desempenho dependem do nível de energia. De acordo com Kidd et al. (2005), o maior ganho de peso, a melhor conversão alimentar e os maiores rendimentos (carcaça, peito e porcentagem de gordura abdominal) são obtidos quando os frangos são alimentados com rações de alta densidade de aminoácidos.

As exigências de aminoácidos diferem entre machos e fêmeas (Smith et al., 1998; Albino et al., 1999). Além disso, autores relatam que aves machos e fêmeas respondem de modo semelhante às mudanças nos níveis de metionina das rações (Whitaker et al., 2002). De acordo com Café et al. (2002), o aumento dos níveis de metionina para 115 e $120 \%$ e dos níveis de lisina para 110, 120 e 130\% das recomendações do NRC (1994) promoveu aumento linear no desempenho dos frangos, mas não afetou o rendimento de carcaça. Entretanto, para rendimento de peito, o melhor nível de metionina foi o equivalente a $120 \%$.

Objetivou-se com este trabalho avaliar o desempenho, o rendimento de carcaça e suas partes e a quantidade de gordura abdominal de frangos de corte, machos e fêmeas, alimentados com rações contendo diversos níveis de energia, lisina e metionina + cistina.

\section{Material e Métodos}

Foram utilizados 1.440 pintos de corte machos e fêmeas, linhagem Ross 308, de 1 dia de idade, alojados em boxes com densidade de 10 aves $/ \mathrm{m}^{2}$ (30 aves por boxe) no período de 1 a 45 dias de idade. Como características de desempenho avaliaram-se o ganho de peso, o consumo de ração e a conversão alimentar.

As rações para as fases inicial, de crescimento e de terminação foram fornecidas nos períodos de 1 a 21, 22 a 40 e 41 a 45 dias de idade, respectivamente. Os níveis de metionina, metionina + cistina, arginina, triptofano e treonina das rações foram calculados considerando os resultados das análises dos alimentos (Tabela 1) e os demais níveis nutricionais e as relações percentuais de lisina e aminoácidos foram definidos de acordo com tabela de Rostagno et al. (2000).

As exigências de aminoácidos foram calculadas com base no conceito de proteína ideal, segundo Rostagno et al. (2000). Os níveis nutricionais das dietas para atender às necessidades das aves foram estabelecidos considerando relatos de Lara et al. (2005).

As dietas (tratamentos) foram formuladas com níveis de energia baixos, médios ou altos combinados com níveis de aminoácidos (lisina e metionina + cistina) idênticos ou $10 \%$ superiores aos descritos por Lara et al. (2005): dieta A - baixo nível de energia e nível de aminoácidos padrão; dieta $\mathrm{B}$ - baixo nível de energia e nível de aminoácidos $10 \%$ superior ao padrão; dieta C nível médio de energia e nível de aminoácidos padrão; dieta D - nível médio de energia e nível de aminoácidos $10 \%$ superior ao padrão; dieta $\mathrm{E}$ - alto nível de energia e nível de aminoácidos padrão; dieta $\mathrm{F}$ - alto nível de energia e nível de aminoácidos $10 \%$ superior ao padrão (Tabelas 2, 3 e 4).

Tabela 1 - Valores dos aminoácidos totais e digestíveis dos alimentos

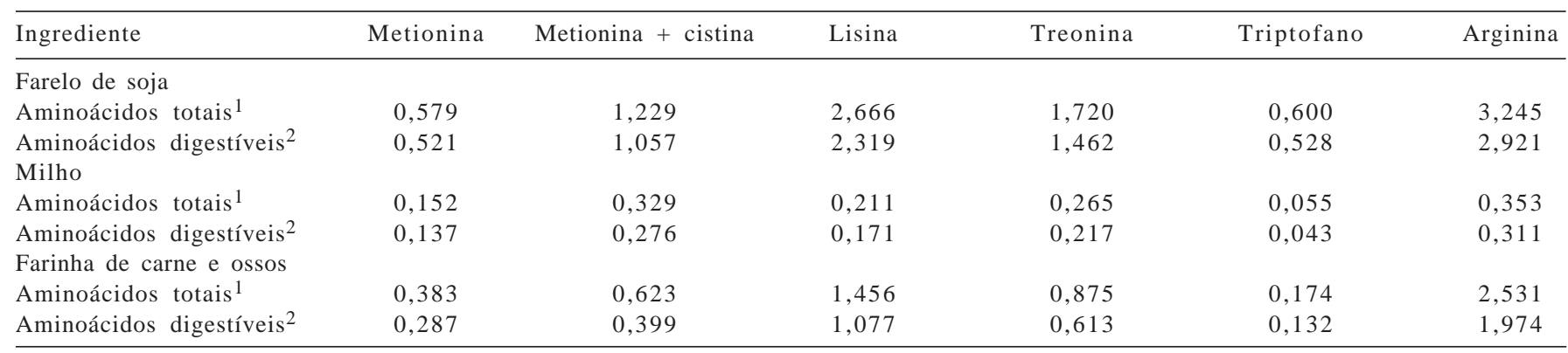

\footnotetext{
${ }^{1}$ Aminoácidos totais analisados pela Degussa.
}

2 Aminoácidos digestíveis calculados de acordo com "CD Aminodat 2.0" - Degussa. 
Tabela 2 - Composição das rações fornecidas na fase inicial (1 a 21 dias de idade)

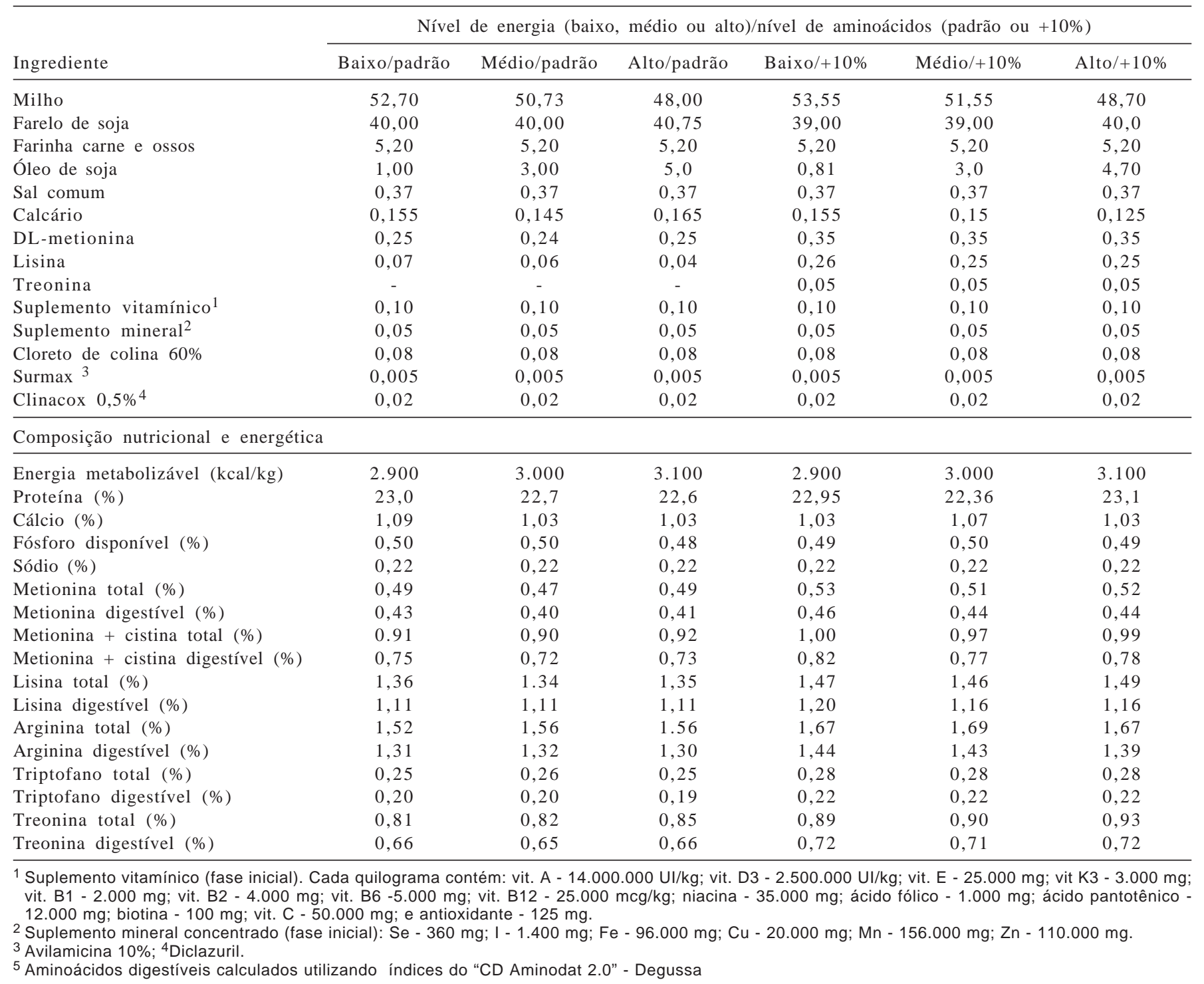

Aos 45 dias de idade, após jejum de ração de 12 horas, foram abatidas 192 aves (96 de cada sexo) para as avaliações dos rendimentos de carcaça limpa e eviscerada (com pés, cabeça e pescoço) e de vísceras (coração, intestino, fígado e moela), considerando o peso vivo em jejum obtido antes do abate. Na avaliação dos rendimentos de cortes (coxa+sobrecoxa, peito, dorso, asa, pés/cabeça/pescoço) e gordura abdominal, o rendimento foi considerado em relação ao peso da carcaça eviscerada.

O delineamento experimental foi inteiramente ao acaso, em esquema fatorial $3 \times 2$, composto de três níveis de energia (baixo, médio ou alto) e dois níveis de aminoácidos (padrão ou $10 \%$ superior ao padrão), com seis tratamentos e oito repetições (quatro para machos e quatro para fêmeas), cada uma com 30 aves. Para as avaliações dos rendimentos de carcaça e vísceras e da porcentagem de gordura abdo- minal, o delineamento foi constituído de seis tratamentos, cada um com 16 repetições. Os dados referentes aos machos e às fêmeas foram analisados, comparados e interpretados separadamente. As diferenças entre as médias foram avaliadas pelo teste de Student-Newman-Keuls (SNK) a 5\% de probabilidade (Sampaio, 2002).

\section{Resultados e Discussão}

Houve interação níveis de energia × níveis de aminoácidos das dietas, tanto para machos quanto para fêmeas aos 40 dias de idade (Tabela 5). Quando alimentados com rações contendo níveis energéticos baixos e médios e níveis de aminoácidos $10 \%$ acima da exigência da ave, os machos aumentaram $(\mathrm{P}<0,05)$ o ganho de peso aos 40 dias de idade. Essa diferença não foi observada com a dieta de alta energia. 
Tabela 3 - Composição das rações fornecidas na fase de crescimento (22 a 40 dias de idade)

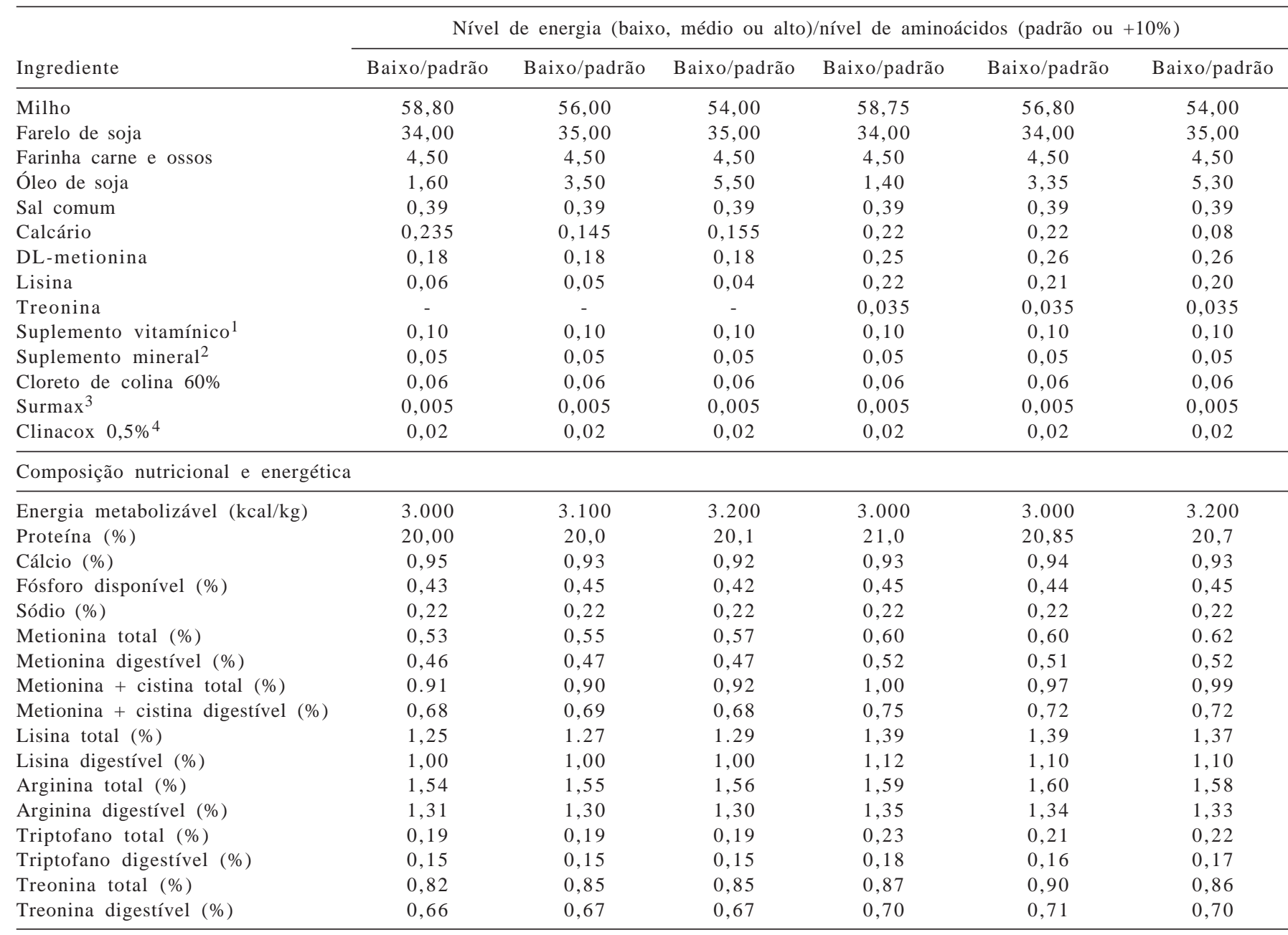

${ }^{1}$ Suplemento vitamínico (Fase crescimento). Cada quilograma contém: vit. A - 10.000 .000 UI/kg; vit. D3 - 2.000.000 UI/kg; vit. E - $20.000 \mathrm{mg} ;$ vit. K3 $2.000 \mathrm{mg}$; vit. B1 - $2.000 \mathrm{mg}$; vit. B2 - $4.000 \mathrm{mg}$; vit. B6 - $4.000 \mathrm{mg}$; vit. B12 - $20.000 \mathrm{mcg} / \mathrm{kg}$; niacina - $30.000 \mathrm{mg}$; ácido fólico - $1.000 \mathrm{mg}$; ácido pantotênico $10.000 \mathrm{mg}$; biotina - $60 \mathrm{mg}$; vit. C - $50.000 \mathrm{mg}$; e antioxidante $-125 \mathrm{mg}$.

2 Suplemento mineral concentrado (fase crescimento): Se - $360 \mathrm{mg}$; I - $1.400 \mathrm{mg}$; Fe - $96.000 \mathrm{mg} ; \mathrm{Cu}-20.000 \mathrm{mg} ; \mathrm{Mn}-156.000 \mathrm{mg} ; \mathrm{Zn}-110.000 \mathrm{mg}$

${ }^{3}$ Avilamicina $10 \% ;{ }^{4}$ Diclazuril.

5 Aminoácidos digestíveis calculados utilizando índices do "CD Aminodat 2.0" - Degussa.

As fêmeas apresentaram maiores ganhos de peso aos 40 dias de idade quando alimentadas com rações com altos níveis de energia e níveis normais de aminoácidos.

Quando o nível de aminoácidos aumentou em 10\%, os níveis médios e altos de energia promoveram melhores resultados, o que confirma os resultados obtidos por Longo et al. (2006), que determinaram maiores necessidades energéticas para fêmeas, além de melhora no ganho de peso de aves alimentadas com rações com maiores níveis de energia. Esses resultados foram semelhantes aos observados por Langhout \& Wijtten (2005), Wijtten et al. (2004) e Kidd et al. (2005), que observaram que, com o aumento da densidade dos aminoácidos, aumenta o ganho de peso corporal, no entanto, nos estudos realizados por Wijtten et al. (2004) e Kidd et al. (2005), os níveis de energia foram fixos e apenas a densidade de aminoácidos variou entre as dietas. Os resultados sugerem que as respostas ao aumento de aminoácidos essenciais dependem do nível dietético de energia.

O ganho de peso dos machos de 1 a 45 dias de idade não diferiu $(\mathrm{P}>0,05)$ entre os níveis de aminoácidos, independentemente do nível de energia, utilizados na ração. $\mathrm{O}$ menor ganho de peso foi observado nos frangos alimentados com rações com baixo nível de energia, independentemente das concentrações de aminoácidos. Esses achados corroboram os descritos por Vasconcelos \& Santos (1997) e Whitaker et al. (2002). Entretanto, Mendes et al. (2004) e Silva Filha et al. (2004) verificaram que a utilização de níveis crescentes de energia não aumentou o ganho de peso de frangos de corte.

As fêmeas tiveram $(\mathrm{P}<0,05)$ maior ganho de peso quando alimentadas com o nível mais alto de aminoácidos. Naquelas 
Tabela 4 - Composição das rações fornecidas na fase de terminação (41 a 45 dias de idade)

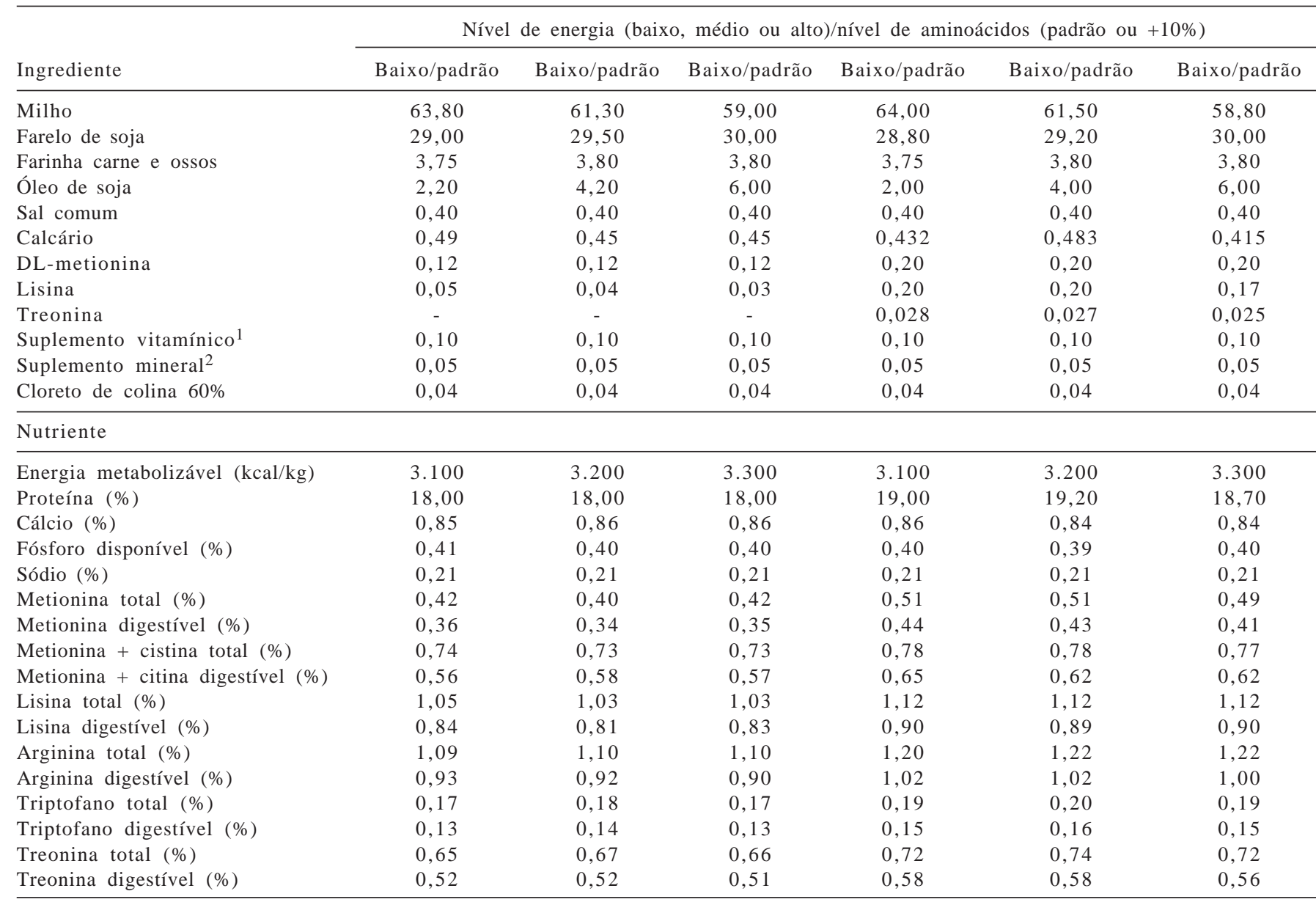

${ }^{1}$ Suplemento vitamínico (fase final). Cada quilograma contém: vit. A - $8.000 .000 \mathrm{UI} / \mathrm{kg}$; vit. D3 - 1.500.000 Ul/kg; vit. E - $15.000 \mathrm{mg} ;$ vit. K3 - $2.000 \mathrm{mg}$ vit. B1 - $1.000 \mathrm{mg}$; vit. B2 - $3.000 \mathrm{mg}$; vit. B6 - $2.000 \mathrm{mg}$; vit. B12 - $15.000 \mathrm{mcg} / \mathrm{kg}$; niacina - $20.000 \mathrm{mg}$; ácido fólico - $500 \mathrm{mg}$; ácido pantotênico - $8.000 \mathrm{mg}$ biotina - $40 \mathrm{mg}$; vit.C - $50.000 \mathrm{mg}$; antioxidante $-125 \mathrm{mg}$

2 Suplemento mineral concentrado (fase final): Se - $360 \mathrm{mg}$; I $1.400 \mathrm{mg}$; Fe - $96.000 \mathrm{mg}$; Cu -20.000 mg; Mn - $156.000 \mathrm{mg} ; \mathrm{Zn}-110.000 \mathrm{mg}$.

3 Aminoácidos digestíveis calculados utilizando-se índices do "CD Aminodat 2.0" - Degussa.

Tabela 5 - Ganho de peso de frangos de corte machos e fêmeas nas fases de 1 a 40 e de 1 a 45 dias de idade

\begin{tabular}{|c|c|c|c|c|c|c|c|c|}
\hline \multirow{3}{*}{$\begin{array}{l}\text { Nível de } \\
\text { aminoácido }\end{array}$} & \multicolumn{8}{|c|}{ Nível de energia da ração } \\
\hline & \multicolumn{8}{|c|}{1 a 40 dias de idade } \\
\hline & Baixo & Médio & Alto & Média & Baixo & Médio & Alto & Média \\
\hline Padrão & $2.484 \mathrm{Bb}$ & $2.542 \mathrm{Bb}$ & $2.664 \mathrm{Aa}$ & 2.563 & $2.042 \mathrm{Ab}$ & $2.055 \mathrm{Bb}$ & $2.162 \mathrm{Aa}$ & 2.086 \\
\hline$+10 \%$ & $2.563 \mathrm{Ab}$ & $2.709 \mathrm{Aa}$ & $2.658 \mathrm{Aa}$ & 2.643 & $2.077 \mathrm{Ab}$ & $2.172 \mathrm{Aa}$ & $2.144 \mathrm{Aa}$ & 2.131 \\
\hline CV (\%) & \multicolumn{8}{|c|}{1 a 45 dias de idade } \\
\hline Padrão & 2.996 & 3.163 & 3.183 & $3.114 \mathrm{~A}$ & 2.478 & 2.499 & 2.584 & $2.520 \mathrm{~B}$ \\
\hline$+10 \%$ & 3.081 & 3.155 & 3.225 & $3.154 \mathrm{~A}$ & 2.500 & 2.577 & 2.624 & $2.567 \mathrm{~A}$ \\
\hline Média & $3.038 b$ & $3.159 a$ & $3.204 \mathrm{a}$ & & $2.489 \mathrm{~b}$ & $2.538 b$ & $2.604 \mathrm{a}$ & \\
\hline
\end{tabular}

\footnotetext{
$\mathrm{A}, \mathrm{B}$ Letras diferentes na coluna diferem $(\mathrm{P}<0,05)$ pelo teste $\mathrm{SNK}$.
}

$a, b$ Letras diferentes na linha diferem $(P<0,05)$ pelo teste SNK. 
alimentadas com rações com níveis altos de energia, o ganho de peso foi estatisticamente superior ao daquelas alimentadas com as rações com os níveis médio e baixo de energia, resultados que confirmam os encontrados por Moran \& Bilgili (1989) e Albino et al. (1999) de que maiores níveis de aminoácidos afetam o desempenho e promovem maior deposição de carne, além de aumento no ganho de peso da ave.

Nos dois períodos avaliados, o consumo de ração (Tabela 6) pelas fêmeas não foi influenciado $(\mathrm{P}>0,05)$ pelos níveis energéticos e aminoacídicos das dietas, portanto, não houve também interação. Nos machos, não houve interação níveis de aminoácidos $\times$ níveis de energia para o consumo de ração. Entretanto, o menor consumo de ração dos machos, em ambos os períodos, foi obtido com o menor nível de energia $(\mathrm{P}<0,05)$. O maior consumo pode estar relacionado ao maior nível de óleo nas rações de média e alta energia, o que aumenta a palatabilidade, favorece a ingestão de ração e promove aumento do consumo. Os resultados obtidos para os machos foram semelhantes aos observados por Moura (2003). Além disso, no período de 1 a 40 dias de idade, os machos responderam significativamente ao aumento dos níveis dos aminoácidos, independentemente do nível de energia. No período de 1 a 45 dias de idade, no entanto, os níveis de aminoácidos não influenciaram o consumo. Esses achados diferem dos encontrados por Langhout \& Wijtten (2005), que, ao fornecerem dietas com níveis mais altos de aminoácidos, observaram redução no consumo, concomitantemente ao aumento do nível energético.

A conversão alimentar (Tabela 7), tanto dos machos quanto das fêmeas, nos períodos de 1 a 40 e de 1 a 45 dias de idade não foi influenciada $(\mathrm{P}>0,05)$ pelos níveis

Tabela 6 - Consumo de ração $(\mathrm{g})$ em frangos de corte machos e fêmeas nas fases de 1 a 40 e de 1 a 45 dias de idade

\begin{tabular}{|c|c|c|c|c|c|c|c|c|}
\hline \multirow{3}{*}{$\begin{array}{l}\text { Nível de } \\
\text { aminoácido }\end{array}$} & \multicolumn{8}{|c|}{ Nível de energia } \\
\hline & \multicolumn{8}{|c|}{1 a 40 dias de idade } \\
\hline & Baixo & Médio & Alto & Média & Baixo & Médio & Alto & Média \\
\hline Padrão & 4.023 & 4.091 & 4.200 & $4.105 B$ & 3.511 & 3.473 & 3.594 & $3.526 \mathrm{~A}$ \\
\hline$+10 \%$ & 4.112 & 4.242 & 4.195 & $4.183 \mathrm{~A}$ & 3.547 & 3.610 & 3.547 & $3.568 \mathrm{~A}$ \\
\hline \multirow[t]{2}{*}{ CV (\%) } & \multicolumn{4}{|c|}{1,5} & \multicolumn{4}{|c|}{1,5} \\
\hline & \multicolumn{8}{|c|}{1 a 45 dias de idade } \\
\hline Padrão & 5.114 & 5.298 & 5.301 & $5.227 \mathrm{~A}$ & 4.461 & 4.423 & 4.511 & $4.465 \mathrm{~A}$ \\
\hline$+10 \%$ & 5.154 & 5.232 & 5.293 & $5.114 \mathrm{~A}$ & 4.456 & 4.535 & 4.523 & $4.505 \mathrm{~A}$ \\
\hline Média & $5.134 b$ & $5.265 a$ & $5.297 a$ & & $4.459 a$ & $4.479 a$ & $4.517 \mathrm{a}$ & \\
\hline
\end{tabular}

$A, B$ Letras diferentes na coluna diferem $(P<0,05)$ pelo teste SNK.

$a, b$ Letras diferentes na linha diferem $(P<0,05)$ pelo teste SNK.

Tabela 7 - Conversão alimentar $(\mathrm{kg} / \mathrm{kg})$ de machos e fêmeas de 1 a 40 dias de idade

\begin{tabular}{|c|c|c|c|c|c|c|c|c|}
\hline \multirow{3}{*}{$\begin{array}{l}\text { Nível de } \\
\text { aminoácido }\end{array}$} & \multicolumn{8}{|c|}{ Nível de energia } \\
\hline & \multicolumn{8}{|c|}{1 a 40 dias de idade } \\
\hline & Baixo & Médio & Alto & Média & Baixo & Médio & Alto & Média* \\
\hline Padrão & 1,62 & 1,61 & 1,58 & 1,60 & 1,72 & 1,69 & 1,66 & 1,69 \\
\hline \multirow[t]{2}{*}{ CV (\%) } & \multicolumn{4}{|c|}{1,8} & \multicolumn{4}{|c|}{2,6} \\
\hline & \multicolumn{8}{|c|}{1 a 45 dias de idade } \\
\hline Padrão & 1,71 & 1,67 & 1,67 & 1,68 & 1,80 & 1,77 & 1,74 & 1,77 \\
\hline$+10 \%$ & 1,67 & 1,66 & 1,64 & 1,66 & 1,78 & 1,76 & 1,72 & 1,75 \\
\hline Média* & 1,69 & 1,67 & 1,65 & & 1,79 & 1,76 & 1,73 & \\
\hline
\end{tabular}

* NS = não-significativo. 
energéticos e aminoacídicos. Os resultados obtidos nos níveis energéticos diferem dos verificados por Braga \& Baião (2001) e Mendes et al. (2004), que observaram melhor conversão alimentar ao fornecerem ração com níveis energéticos mais altos. Os resultados observados considerando os níveis de aminoácidos estão de acordo com os descritos por Reginatto et al. (2000), que também não notaram diferenças entre níveis de aminoácidos sulfurados e treonina utilizados na alimentação de frangos de corte. Entretanto, esses resultados diferem dos encontrados por Kidd et al. (2005), que observaram melhor conversão alimentar quando forneceram níveis de aminoácidos mais altos.

O rendimento de carcaça dos machos não apresentou interações $(\mathrm{P}>0,05)$ entre os níveis energéticos e níveis de aminoácidos. Os melhores rendimentos foram obtidos com nível baixo e médio de energia; entre os níveis médio e alto, não foram observadas diferenças. Além disso, os níveis de aminoácidos não influenciaram $(\mathrm{P}>0,05)$ o rendimento de carcaça dos machos. Os dados de rendimento de carcaça das fêmeas revelaram interação significativa níveis de aminoácidos $\times$ níveis de energia. As aves alimentadas com o nível médio de energia responderam positivamente ao aumento dos aminoácidos, enquanto naquelas alimentadas com o nível mais alto de energia o rendimento de carcaça piorou com o aumento dos níveis de aminoácidos. Estes resultados podem ser explicados pela relação ideal entre níveis mais altos de aminoácidos e o nível médio de energia, que favorece o rendimento de carcaça. Estes resultados foram semelhantes aos achados de Wijtten et al. (2001) e Whitaker et al. (2002), mas diferem dos obtidos por Kidd et al.(2005).

O rendimento de peito dos machos não foi afetado $(\mathrm{P}>0,05)$ pelos níveis de energia das dietas. Contudo, independentemente dos níveis energéticos, o maior rendimento de peito $(\mathrm{P}<0,05)$ foi observado quando os frangos receberam o nível mais alto de aminoácidos, o que está de acordo com relatos de Café et al. (2002) e Wijtten et al. (2004) de que níveis mais altos de treonina e lisina aumentam o rendimento de peito. Os dados de rendimento de peito das fêmeas revelaram interação significativa $(\mathrm{P}<0,05)$ níveis de energia $\times$ níveis de aminoácidos, uma vez que o melhor rendimento foi observado com o maior nível de energia e

Tabela 8 - Rendimentos de carcaça (\%) e peito (\%) de frangos de corte machos e fêmeas aos 45 dias de idade

\begin{tabular}{|c|c|c|c|c|c|c|c|c|}
\hline \multirow{3}{*}{$\begin{array}{l}\text { Nível de } \\
\text { aminoácido }\end{array}$} & \multicolumn{8}{|c|}{ Nível de energia } \\
\hline & \multicolumn{8}{|c|}{ Rendimento de carcaça } \\
\hline & Baixo & Médio & Alto & Média & Baixo & Médio & Alto & Média \\
\hline Padrão & 87,7 & 86,3 & 85,4 & $86,5 \mathrm{~A}$ & $86,5 \mathrm{Aa}$ & $85,9 B \mathrm{~B}$ & 87,9Aa & 86,8 \\
\hline \multirow[t]{2}{*}{ CV (\%) } & \multicolumn{4}{|c|}{4,5} & & \multicolumn{2}{|c|}{2,8} & \\
\hline & \multicolumn{8}{|c|}{ Rendimento de peito } \\
\hline Padrão & 33,0 & 34,0 & 34,1 & $33,7 \mathrm{~B}$ & $35,8 \mathrm{Aa}$ & 36,9Aa & $34,9 \mathrm{Ba}$ & 35,9 \\
\hline$+10 \%$ & 35,1 & 36,0 & 34,7 & $35,3 \mathrm{~A}$ & 36,9Аа & $36,4 \mathrm{Aa}$ & 36,9Аа & 36,7 \\
\hline Média & $34,0 a$ & $35,0 a$ & $34,4 a$ & & 36,4 & 36,7 & 35,9 & \\
\hline
\end{tabular}

$\mathrm{A}, \mathrm{B}$ Letras diferentes na coluna diferem $(\mathrm{P}<0,05)$ pelo teste $\mathrm{SNK}$.

$a, b$ Letras diferentes na linha diferem $(P<0,05)$ pelo teste SNK.

Tabela 9 - Rendimento de coxa+sobrecoxa de frangos de corte machos e fêmeas aos 45 dias de idade (\%)

\begin{tabular}{|c|c|c|c|c|c|c|c|c|}
\hline \multirow{2}{*}{$\begin{array}{l}\text { Nível de } \\
\text { aminoácido }\end{array}$} & \multicolumn{7}{|c|}{ Nível de energia } & \\
\hline & Baixo & Médio & Alto & Média & Baixo & Médio & Alto & Média* \\
\hline Padrão & 25,9 & 26,5 & 26,8 & 26,4 & 25,1 & 25,0 & 24,1 & 24,7 \\
\hline$+10 \%$ & 25,9 & 26,5 & 25,8 & 26,0 & 24,9 & 25,0 & 24,6 & 24,8 \\
\hline Média* & 25,9 & 26,5 & 26,3 & & 25,00 & 25,0 & 24,4 & \\
\hline
\end{tabular}

* NS = não-significativo. 
Tabela 10 - Porcentagem de gordura abdominal de frangos machos e fêmeas aos 45 dias de idade

\begin{tabular}{|c|c|c|c|c|c|c|c|c|}
\hline \multirow{2}{*}{$\begin{array}{l}\text { Nível de } \\
\text { aminoácido }\end{array}$} & \multicolumn{7}{|c|}{ Nível de energia } & \\
\hline & Baixo & Médio & Alto & Média & Baixo & Médio & Alto & Média* \\
\hline 1 & 0,93 & 1,02 & 1,11 & 1,02 & 1,23 & 1,22 & 1,40 & 1,28 \\
\hline 2 & 1,08 & 1,04 & 1,07 & 1,06 & 1,23 & 1,26 & 1,27 & 1,25 \\
\hline Média* & 1,00 & 1,03 & 1,09 & & 1,23 & 1,24 & 1,33 & \\
\hline
\end{tabular}

* NS = não-significativo.

aminoácidos. Entretanto, Stringhini et al. (1998), Langhout \& Wittjen (2005) e Kidd et al. (2005) não observaram influência dos níveis de aminoácidos sobre o rendimento de peito, tanto nos machos quanto nas fêmeas.

Os rendimentos de coxa+sobrecoxa dos machos e das fêmeas não foram influenciados $(\mathrm{P}>0,05)$ pelos níveis de energia e aminoácidos. Os achados deste trabalho diferem dos relatados por Mendes et al. (2004), que observaram pior rendimento de coxa+sobrecoxa quando fornecidos níveis mais baixos de aminoácidos.

A porcentagem de gordura abdominal, tanto nos machos como nas fêmeas, não foi afetada $(\mathrm{P}>0,05)$ pelos níveis de energia e aminoácidos das rações. Estes dados estão de acordo com os achados de Langhout \& Wijtten (2005), mas diferem dos observados por Leeson et al. (1996) e Kidd et al. (2005).

\section{Conclusões}

Em frangos de corte machos, os níveis energéticos mais indicados para maior peso aos 45 dias de idade são 3.000, 3.100 e $3.200 \mathrm{kcal} / \mathrm{kg}$ de ração nas fases inicial, de crescimento e de terminação, respectivamente, com nível de aminoácido normal. Maior rendimento de peito foi obtido com níveis médios de energia associados a níveis 10\% mais altos de aminoácidos. Em fêmeas, os melhores níveis para ganho de peso até 40 dias de idade são 3.000, 3.100 e $3.200 \mathrm{kcal} / \mathrm{kg}$ de ração nas fases inicial, de crescimento e de terminação, respectivamente, associados a valores mais altos de aminoácidos (10\% acima do recomendado) e, para maior ganho de peso até os 45 dias de idade, devem ser associados níveis altos de energia e níveis mais altos de aminoácidos nas rações.

\section{Literatura Citada}

ALBINO, L.F.T.; SILVA, S.H.M.; VARGAS JR., J.G. et al. Níveis de metionina + cistina para frangos de corte de 1 a 21 e 22 a 42 dias de idade. Revista Brasileira de Zootecnia, v.28, n.2, p.519-25, 1999.
BRAGA, J.P.; BAIÃO, N.C. Suplementação lipídica no desempenho de aves em altas temperaturas. Cadernos Técnicos de Veterinária e Zootecnia UFMG, v.31, p.23-28, 2001.

CAFÉ, M.B.; WALDROUP, P.W.; JUNQUEIRA, O.M. et al. Interação entre diferentes níveis dietéticos de metionina e de lisina na nutrição de frangos de corte. In: CONFERÊNCIA APINCO DE CIÊNCIA E TECNOLOGIA AVÍCOLAS, 2002. Campinas. Anais... Campinas: Fundação Apinco de Ciência e Tecnologia Avícola, 2002. p.67.

KIDD, M.T.; CORZO A.; HOEHLER, D. et al. Broiler responsiveness (Ross x 708) to diets varying in amino acid density. Poultry Science, v.84, n.4, p.1389-1396, 2005.

LANGHOUT, D.J.; WIJTTEN, P.J.A. Efeitos da nutrição sobre a qualidade da carne e da gordura. In: CONFERÊNCIA APINCO DE CIÊNCIA E TECNOLOGIA AVÍCOLAS, 23., 2005. Campinas. Anais... Campinas: Fundação APINCO de Ciência e Tecnologia Avícola, 2005. p.21-31.

LARA, J.C.L.; BAIÃO, N.C.; AGUILAR, C.A.L. et al. Efeito das fontes lipídicas adicionadas às dietas sobre o desempenho de frangos de corte. Arquivo Brasileiro de Veterinária e Zootecnia, v.57, p.792-798, 2005.

LEESON, S.; CASTON, L.; SUMMERS, J.D. Broiler response to diet energy. Poultry Science, v.75, n.4, p.529-535, 1996.

LESSON, S.; SUMMERS, J.D. Nutrition of the chicken. 4.ed. Guelph: University Books, 2001. 413p.

LEMME, A. El “Concepto de proteína ideal” en la nutrición de pollos. Datos experimentales con niveles variables de proteína ideal dietética. AminoNews Degussa AG, v.4, n.2, p.1-10, 2003.

LONGO, F.A.; SAKOMURA, N.K.; RABELLO, C.B.V. et al. Exigências energéticas para mantença e para o crescimento de frangos de corte. Revista Brasileira de Zootecnia, v.35, n.13, p.119-125, 2006.

LUCHESI, J.B. Nutrição de frangos de corte. In: CONFERÊNCIA APINCO DE CIÊNCIA E TECNOLOGIA AVÍCOLAS, 18., 2000. Campinas. Anais... Campinas: Fundação APINCO de Ciência e Tecnologia Avícola, 2000. p.11-33.

MENDES, A.A.; MOREIRA, J.; OLIVEIRA, E.G. et al. Efeitos da energia da dieta sobre desempenho, rendimento de carcaça e gordura abdominal de frangos de corte. Revista Brasileira de Zootecnia, v.33, n.6, p.2300-2307, 2004 (supl. 3).

MORAN, E.T. Nutrição e sua relação com a qualidade de carcaça de frangos de corte. In: CONFERÊNCIA APINCO DE CIÊNCIA E TECNOlOGiA AVÍCOlA, 10., 1992, Santos. Anais... Campinas: Fundação Apinco de Ciência e Tecnologia Avícolas, 1992. p.37-44.

MORAN, E.T.; BILGILI, S.F. Processing losses, carcass quality and meat yields of broiler chickens receiving diets marginally deficient to adequate in lysine prior to marketing. Poultry Science, v.69, n.5, p.702-710, 1989.

MOURA, B.H.S. Desempenho e composição da carcaça de frangos de corte alimentados com diferentes níveis energéticos, com e sem óleo. Belo Horizonte: Universidade Federal de Minas Gerais, 2003. 51p. Dissertação (Mestrado em Medicina Veterinária) - Universidade Federal de Minas Gerais, 2003. 
REGinATTO, M.F.; RIBEIRO, A.M.L.; PENZ JR., A.M. et al Suplementação de treonina em dietas de frangos de corte, variando a energia e as relações energia:proteína. Revista Brasileira de Ciência Avícola, v.2, n.3, p.239-247, 2000.

ROSTAGNO H.S.; ALBINO L.F.T.; DONZELE J.L. et al. Tabela brasileira para aves e suínos: composição de alimentos e exigências nutricionais. 2.ed. Viçosa, MG: Editora UFV, 2000. $186 \mathrm{p}$.

SAMPAIO, I.B.M. Estatística aplicada à experimentação animal. 2.ed. Belo Horizonte: FEPMVZ Editora, 2002. 265p.

SILVA FILHA, O.L.; BARBOZA, W.A.; FARIAS FILHO, R.V. et al. Efeito do nível energético da ração sobre o desempenho de frangos de corte no período de um a 21 dias de idade. Revista da Faculdade de Zootecnia, Veterinária, Agronomia de Uruguaiana, v.11, n.1, p.7-20, 2004.

SMITH, E.R.; PESTI, G.M.; BAKALLI, R.I. et al. Further studies on the influence of genotype and dietary protein on the performance of broilers. Poultry Science, v.77, n.11, p.1678-87, 1998.

STRINGHINI, J.H.; ARIKI, J.; CAFÉ, M.B. et al. [1998]. Efeito dos níveis de aminoácidos sulfurados e de lisina para frangos de corte criados em duas densidades populacionais.
Disponível em: <http://www.sbz.org.br/eventos/PortoAlegre/ homepagesbz/Nut\%5CNUT040.htm> Acesso em: 14/5/2005.

VASCONCELOS, R.Q.; SANTOS, M.W. Efeito de níveis de energia e proteína da dieta sobre o desempenho de frangos de corte na fase inicial. In: REUNIÃO ANUAL DA SOCIEDADE BRASILEIRA DE ZOOTECNIA, 34., 1997, Juiz de Fora. Anais... Juiz de Fora: Sociedade Brasileira de Zootecnia, 1997. p.6-8.

WHITAKER, H.M.A; MENDES A.A.; GARCIA E.A. et al. Efeito da suplementação de metionina sobre o desempenho e a avaliação de carcaças de frangos de corte. Revista Brasileira de Ciência Avícola, v.4, n.1, p.1-9, 2002.

WIJTTEN, P.J.A.; LEMME, A.; PACK, M. et al. The effect of enhanced dietary ideal amino acid levels in maize- and wheat-based diets on performance of male and female broilers. In: EUROPEAN SYMPOSIUM OF POULTRY NUTRITION, 13., 2001, Blankenberge. Proceedings... Blankenberge: 2001. p.41-42.

WIJTTEN, P.J.A.; LEMME, A.; LANGHOUT, D.J. Effects of different dietary ideal protein levels on male and female broiler performance during different phases of life: single phase effects, carryover effects, and interactions between phases. Poultry Science, v.83, n.12, p.2005-2015, 2004. 